\title{
Educação ambiental e educação infantil em dissertações e teses brasileiras: conhecimentos, valores e participação política presentes nas práticas pedagógicas relatadas
}

Marinete Belluzzo Luccas marineteluccas@gmail.com orcid.org/0000-0002-5886-6072 Universidade Estadual Paulista (Unesp), Rio Claro, São Paulo, Brasil

Dalva Maria Bianchini Bonotto $\frac{\text { dalva.mb.bonotto@unesp.br }}{\text { orcid.org/0000-0001-6238-7157 }}$ Universidade Estadual Paulista (Unesp), Rio Claro, São Paulo, Brasil

\section{RESUMO}

Esse artigo é um recorte da pesquisa de mestrado vinculada ao projeto interinstitucional denominado Educação ambiental no Brasil: análise da produção acadêmica (dissertações e teses) - EArte. A pesquisa se fundamenta na Teoria Histórico-Cultural para compreender a aprendizagem e o desenvolvimento infantil, e na perspectiva de uma Educação Ambiental Crítica, que contemple três dimensões: conhecimentos, valores éticos e estéticos e participação política. Buscamos identificar e analisar a presença dessas três dimensões nas práticas pedagógicas em educação ambiental no contexto escolar da educação infantil relatadas em treze dissertações e teses brasileiras. Trata-se de uma pesquisa de natureza qualitativa, caracterizada como pesquisa documental, de caráter bibliográfico, do tipo estado da arte. Em relação à dimensão dos conhecimentos os resultados indicam como temáticas mais abordadas: água, fauna, flora, poluição e resíduos sólidos. A proposta de desenvolver o trabalho por meio de projetos pedagógicos é relatada em onze dos treze trabalhos, mas algumas práticas revelam a ausência de participação das crianças nas decisões sobre o planejamento e a execução desses projetos, o que nos leva a questionar a compreensão desses professores sobre o trabalho por meio de projetos pedagógicos e sobre a construção de conhecimentos pelas crianças. No que se refere à dimensão de valores éticos e estéticos identificamos, por parte dos professores cujas práticas são investigadas, a intenção de formar valores envolvendo: a cooperação, a solidariedade, a autonomia, a sensibilidade, o respeito às diferenças, a afetividade e o cuidado. Práticas pedagógicas que contemplam a dimensão da participação política são relatadas em onze dos treze trabalhos e se efetivam, com mais frequência, no nível individual e no social. As pesquisas indicam a necessidade de uma teoria pedagógica que se alinhe à Educação Ambiental Crítica e ajude o professor a pensar e tomar decisões sobre sua prática.

PALAVRAS-CHAVE: Educação ambiental. Educação infantil. Práticas pedagógicas. 


\section{INTRODUÇÃO}

Quando pensamos em alternativas para enfrentar a crise socioambiental consideramos que é necessário melhorar os padrões de relação ser humanosociedade-natureza, bem como compreender as questões sociais, culturais e econômicas que a fundamentam e que precisam ser superadas e transformadas, no sentido de construir uma sociedade sustentável com equidade e qualidade de vida para todos os seres humanos e não humanos.

Segundo Carvalho (2006, p. 21), propostas de ação têm sido apresentadas "com o objetivo de minimizar, corrigir ou reverter situações de impacto ambiental ou a busca de possíveis transformações radicais dos padrões de relação ser humano-sociedade-natureza". Nesse contexto, o processo educativo, de forma geral, e a educação ambiental, em particular, têm sido apresentados como possibilidades de mudanças e como agentes de transformação do atual quadro de degradação ambiental, devendo, no entanto, que atentemos para suas inerentes limitações.

A educação constitui-se em uma prática social que se estabelece na relação com o outro, com a sociedade e com o meio natural. Nessa relação aprende-se a conviver com o outro, a produzir trabalho e cultura, ou seja, aprende-se a ser humano. Como atividade humana, social e política, a educação manifesta diferentes posicionamentos quanto a seus fins, podendo se apresentar através de um viés conservador ou a partir de uma tendência crítica. Carvalho (2006, p. 21) afirma que "diferentes visões do processo educativo engendram propostas educativas com características próprias" e, consequentemente, diferentes práticas pedagógicas.

Assim como diferentes concepções de educação remetem a práticas pedagógicas diversas, podemos afirmar que diferentes concepções de educação engendram diferentes concepções de educação ambiental que, grosso modo, também podem ser agrupadas em duas grandes tendências: uma conservadora e outra crítica (GUIMARÃES, 2004).

A educação ambiental dita conservadora reflete os paradigmas da sociedade moderna, priorizando o conhecimento científico e metódico da natureza. Segundo Guimarães (2004), essa tendência comporta uma visão dualista, simplista e fragmentada da relação homem-natureza, colocando-os em polos distintos e desconsiderando a diversidade e complexidade dessa relação. Essa concepção de educação ambiental produz uma prática pedagógica focada no indivíduo e na transformação de seu comportamento, acreditando que a sociedade é a soma de seus indivíduos, portanto cada um deve fazer a sua parte.

A necessidade de "uma renovação multidimensional capaz de mudar o conhecimento, os valores culturais e éticos, as instituições, as relações sociais e políticas" (LAYRARGUES; LIMA, 2014, p. 29) conduz a outra vertente da educação ambiental: a concepção crítica. O foco dessa concepção está na dimensão política da questão ambiental. Por essa razão, as práticas pedagógicas devem procurar "contextualizar e politizar o debate ambiental, problematizar as contradições dos modelos de desenvolvimento e de sociedade" (LAYRARGUES; LIMA, 2014, p. 33).

Considerando que os problemas ambientais têm suas origens "nas relações sociais, nos modelos de sociedade e de desenvolvimento prevalecentes" (LAYRARGUES; LIMA, 2014, p. 29) nos posicionamos a favor de uma educação 
ambiental capaz de problematizar esses contextos sociais em sua interface com a natureza. Assim, uma educação ambiental que se pretenda crítica, reflexiva, criadora e transformadora precisa concretizar-se em práticas pedagógicas coerentes com os pressupostos teóricos que fundamentam essa proposta.

Nesse sentido, Carvalho $(1989,1999,2001,2006)$ destaca que, nas propostas para educação ambiental, três dimensões que se inter-relacionam e se complementam precisam ser contempladas:

a) uma primeira dimensão relacionada com a natureza dos conhecimentos a serem trabalhados;

b) uma segunda dimensão relacionada com valores éticos e estéticos envolvendo as questões da natureza;

c) e, por fim, [...] a dimensão política, no sentido de preparar o indivíduo para ações concretas de soluções para os problemas ambientais. (CARVALHO, 1999, p. 36, grifos do autor)

As instituições escolares, tem se apresentado como espaços privilegiados para que a educação ambiental seja desenvolvida. Assim, a educação ambiental tem adentrado os espaços da educação escolar e, desde a segunda metade do século XX, ganhou campo tanto nas pesquisas como nas políticas públicas para a educação básica brasileira.

A Lei 9795, de 27 de abril de 1999, que dispõe sobre a educação ambiental e institui a política nacional de educação ambiental (BRASIL, 1999), estabelece que esta deva ser desenvolvida em todos os níveis e modalidades do ensino formal, incluindo a educação básica que compreende da educação infantil ao ensino médio.

Contudo, as dificuldades encontradas para planejar e promover ações que realmente conduzam a mudanças tem levado a práticas pedagógicas intituladas de educação ambiental, mas "que são descontextualizadas, fragmentadas, improvisadas, permanecendo, muitas vezes, no senso comum e não trazendo contribuição significativa para a formação dos alunos" (SANTANA, 2005, p. 12 apud LUCCAS, 2016, p. 15).

No contexto da educação infantil, que atende crianças de 0 a 5 anos de idade, esse quadro se agrava, considerando que os docentes não são formados para lidar com propostas em educação ambiental (RUFFINO, 2003). Segundo Rodrigues (2011), o maior problema disso é que a maioria desses professores acaba trabalhando com concepções tradicionais (conservadoras) de educação ambiental "o que resulta em propostas de atividades realizadas de forma pontual e descomprometidas com toda a problemática envolvida na ação" (RODRIGUES, 2011, p. 176).

Partindo dos pressupostos de que a educação ambiental no contexto da educação escolar representa uma possibilidade de enfrentamento da crise socioambiental e de que a instituição escolar de educação infantil pode ser o melhor lugar para a educação das crianças pequenas (MELLO, 2007), acreditamos que o planejamento e execução de práticas pedagógicas diversificadas, significativas e que levem em consideração as especificidades e singularidades dessa faixa etária favorecem o trabalho em educação ambiental na educação infantil. 
Apesar de os avanços alcançados em termos de políticas públicas que prescrevem a inserção da educação ambiental no currículo da educação infantil, pesquisas revelam haver certa falta de compromisso em relação ao desenvolvimento da educação ambiental nesse nível da educação básica e, indicam ainda, que a temática ambiental na educação infantil tem sido pouco investigada (ALBERTO, 2007; RODRIGUES, 2011; RUFFINO, 2003).

Diante da relevância desse assunto, faz-se necessário que mais pesquisas sejam realizadas e que seus resultados contribuam para o enriquecimento e a orientação das práticas pedagógicas em educação ambiental na educação infantil. Portanto, a problemática que motiva nossa pesquisa se volta ao que as pesquisas no campo da Educação Ambiental estão trazendo como contribuição para o trabalho de educação ambiental na educação infantil.

Desse modo, entendemos ser apropriado investigar, nas dissertações e teses brasileiras (importantes na produção teórica do campo da Educação Ambiental), como vem se constituindo o tema das práticas pedagógicas em educação ambiental na educação infantil, a fim de buscar compreender quais as especificidades dessas práticas nesse segmento de ensino.

Este artigo é um recorte da pesquisa de mestrado (LUCCAS, 2016) realizada junto ao programa de pós-graduação em Educação da Universidade Estadual Paulista - Unesp - campus de Rio Claro, São Paulo, Brasil, vinculada ao projeto interinstitucional denominado Educação ambiental no Brasil: análise da produção acadêmica (dissertações e teses) - EArte.

A pesquisa se fundamenta na Teoria Histórico-Cultural para compreender a aprendizagem e o desenvolvimento infantil (FOLQUE; MELLO, 2015; MELLO, 1999, 2002, 2007; VIGOTSKI, 2008) e na perspectiva de uma Educação Ambiental Crítica (GUIMARÃES, 2004; LAYRARGUES; LIMA, 2014) que contemple, em suas propostas de trabalho, três dimensões - a dos conhecimentos, a dos valores éticos e estéticos e a da participação política (CARVALHO, 1989, 1999, 2001, 2006). Por meio da leitura de dissertações e teses brasileiras em Educação Ambiental, que descrevem práticas pedagógicas em educação ambiental no contexto escolar da educação infantil, buscamos identificar e analisar a presença dessas três dimensões nas práticas pedagógicas relatadas nesses trabalhos.

Por práticas pedagógicas entendemos as atividades docentes planejadas e intencionalizadas, que partem de pressupostos teóricos sobre educação (TELES; IBIAPINA, 2008 apud LUCCAS, 2016, p. 42), não se resumindo em procedimentos didáticos, mas se concretizando nesses.

\section{PROCEDIMENTOS METODOLÓGICOS}

Trata-se de uma pesquisa de natureza qualitativa, caracterizada como pesquisa documental, de caráter bibliográfico, do tipo estado da arte, com o corpus documental constituído por dissertações e teses brasileiras, que descrevem e analisam práticas pedagógicas em educação ambiental no contexto escolar da educação infantil. Realizamos uma análise do conteúdo dos trabalhos (dissertações e teses), que foram selecionados a partir dos descritores e dos resumos encontrados no catálogo produzido pelo projeto interinstitucional denominado Educação ambiental no Brasil: análise da produção acadêmica 
(dissertações e teses) - EArte (CNPq N. 480328/2010 - 2), ao qual a pesquisa está vinculada. O catálogo do EArte estava organizado, na ocasião da pesquisa no período de 2014 a 2016, a partir da seleção das dissertações e teses em Educação Ambiental, realizadas entre os anos de 1981 a 2012, disponíveis no Banco de Teses da Capes (Comissão de Aperfeiçoamento de Pessoal do Nível Superior).

Trata-se de uma pesquisa qualitativa cuja principal característica é seu caráter compreensivo ou interpretativo (LÜDKE; ANDRÉ, 2015).

Trata-se, ainda, de uma pesquisa documental por adotar como material de pesquisa dissertações e teses. A pesquisa documental, segundo Lüdke e André (2015, p. 44-45), "pode se constituir numa técnica valiosa de abordagem de dados qualitativos". Segundo as mesmas autoras, dos documentos "podem ser retiradas evidências que fundamentem afirmações e declarações do pesquisador"; e, ainda, "surgem num determinado contexto e fornecem informações sobre esse mesmo contexto" (LÜDKE; ANDRÉ, 2015, p. 45).

Por sua vez, a pesquisa do tipo estado da arte ou estado do conhecimento procura mapear a produção acadêmica e analisar como um determinado tema vem sendo discutido nos diferentes campos do conhecimento. Para Romanowski e Ens (2006, p. 39) "esses trabalhos não se restringem a identificar a produção, mas analisá-la, categorizá-la e revelar os múltiplos enfoques e perspectivas".

Para a seleção das dissertações e teses utilizamos o catálogo produzido pelo EArte, disponível no site http://www.earte.net/, utilizando os seguintes descritores: Contexto Educacional, Escolar, Regular e Educação Infantil. Nessa etapa foram selecionados 79 (setenta e nove) trabalhos, sendo 38 (trinta e oito) voltados especificamente à investigação do contexto escolar da educação infantil e 41 (quarenta e um) classificados como trabalhos voltados, também, para outros níveis e etapas do ensino (Ensino Fundamental 1a a 4ạ/1음 ao 5ㅇ, Ensino Fundamental 5a a 8aㅡㅇㅡ ao 9oㅡ, Ensino Médio, Educação Superior). A leitura dos resumos e a leitura flutuante (BARDIN, 2009) dos trabalhos completos disponíveis possibilitaram averiguar a pertinência da manutenção de cada um dos trabalhos no corpus documental.

Selecionamos as dissertações e teses brasileiras que descrevem e analisam práticas pedagógicas em educação ambiental no contexto escolar da educação infantil e cujos trabalhos completos foram localizados para leitura. Esses critérios de seleção são justificados, detalhadamente, na pesquisa completa (LUCCAS, 2016). O corpus documental é constituído por 13 (treze) trabalhos, sendo 11 (onze) dissertações e 02 (duas) teses.

Esses trabalhos foram lidos na íntegra, em busca das respostas aos objetivos da pesquisa, que, no caso deste artigo, foca na caracterização das práticas pedagógicas com relação à presença das dimensões de conhecimento, valores éticos e estéticos e participação política, discutindo as especificidades das práticas pedagógicas em educação ambiental na educação infantil.

Os trabalhos foram analisados por meio do instrumento analítico da análise de conteúdo. A análise de conteúdo é caracterizada como um método de análise do conteúdo simbólico das mensagens. É um instrumento de análise interpretativa, devendo extrapolar um caráter meramente descritivo (LÜDKE; ANDRÉ, 2015). Segundo Bardin (2009), a análise de conteúdo compreende um 
conjunto de técnicas de análise das comunicações, passível de ser adaptado conforme os documentos e os objetivos dos investigadores.

Para caracterizar as práticas pedagógicas em relação à presença das dimensões de conhecimento, valores éticos e estéticos e participação política, definimos essas três dimensões como categorias a priori (MORAES, 2007) e buscamos, no corpus documental, excertos dos textos que apontassem para a presença de tais dimensões em conformidade com o referencial teórico adotado na pesquisa. Esses excertos constituíram as unidades de registro (FRANCO, 2008).

Aqui, faz-se necessário pontuar que não foi realizada uma análise das práticas pedagógicas em si, dada a natureza da pesquisa desenvolvida, mas, sim, das elaborações dos autores das pesquisas sobre essas práticas. Dessa forma, é provável que algumas ações ou procedimentos realizados pelo professor não estejam descritos nos trabalhos analisados.

$\mathrm{Na}$ apresentação e discussão dos resultados, ao nos referirmos às dissertações e teses analisadas, essas serão indicadas a partir de uma letra maiúscula, sendo D para dissertação de mestrado e T para tese de doutorado, e o número ${ }^{1}$ que se segue à letra particulariza cada um desses trabalhos. A relação desses trabalhos com as referências se encontra no quadro 1.

Quadro 1 - Relação das dissertações e teses que compõem o corpus documental

\begin{tabular}{|c|c|}
\hline Código & Referência \\
\hline D2 & $\begin{array}{l}\text { FERNANDES, A. L. Educação ambiental na educação infantil: sentidos } \\
\text { produzidos no cotidiano. 2007. } 141 \text { f. Dissertação (Mestrado em Educação), } \\
\text { Centro de Educação, Universidade Federal do Espírito Santo, Vitória, } 2007 .\end{array}$ \\
\hline D8 & $\begin{array}{l}\text { TERRA, C. L. O processo de construção das identidades surdas em uma escola } \\
\text { especial para surdos sob a ótica das três ecologias. 2011. } 156 \text { f. Dissertação } \\
\text { (Mestrado em Educação Ambiental), Universidade Federal do Rio Grande, Rio } \\
\text { Grande, } 2011 .\end{array}$ \\
\hline D9 & $\begin{array}{l}\text { SCHUCH, D. S. O ambiente escolar na formação ecológica da criança. } 2009 . \\
153 \text { f. Dissertação (Mestrado em Educação), Universidade do Vale do Itajaí, } \\
\text { Itajaí, } 2009 .\end{array}$ \\
\hline D17 & $\begin{array}{l}\text { SILVA, J. M. R. Compostagem de resíduos sólidos domiciliares e horta } \\
\text { comunitária como instrumento de educação ambiental em escola municipal } \\
\text { de educação infantil de Bauru (SP). 2001. } 108 \text { f. Dissertação (Mestrado em } \\
\text { Educação para a Ciência), Faculdade de Ciências da Universidade Estadual } \\
\text { Paulista, Bauru, 2001. }\end{array}$ \\
\hline D21 & $\begin{array}{l}\text { BARBOSA, M. M. O sentimento é dor, o riso é felicidade e a educação } \\
\text { ambiental é-sendo-isso-aí-mesmo-cuidado: O (des)velarse "discentes- } \\
\text { docente-pesquisadora" em uma sala de aula de Educação Infantil do Sistema } \\
\text { Municipal de Ensino de Vitória (ES). 2006. } 280 \text { f. Dissertação (Mestrado em } \\
\text { Educação), Centro de Educação, Universidade Federal do Espírito Santo, } \\
\text { Vitória, 2006. }\end{array}$ \\
\hline D25 & $\begin{array}{l}\text { PEREIRA, M. H. B. Educação Ambiental: as elaborações das crianças de seis } \\
\text { anos. 2011. } 119 \text { f. Dissertação (Mestrado em Educação), Faculdade de } \\
\text { Educação, Universidade Estadual de Campinas, Campinas, } 2011 .\end{array}$ \\
\hline D26 & $\begin{array}{l}\text { FLEIG, M. T. Educandos e educadoras no diálogo: uma investigação da } \\
\text { educação ambiental na infância. 2003. } 171 \text { f. Dissertação (Mestrado em } \\
\text { Educação), Centro de Educação, Universidade Federal de Santa Maria, Santa } \\
\text { Maria, 2003. }\end{array}$ \\
\hline D28 & $\begin{array}{l}\text { ALBERTO, P. G. Educação ambiental e educação infantil numa área de } \\
\text { proteção ambiental: concepções e práticas. 2007. } 196 \text { f. Dissertação }\end{array}$ \\
\hline
\end{tabular}




\begin{tabular}{|c|c|}
\hline Código & Referência \\
\hline & $\begin{array}{l}\text { (Mestrado em Educação), Instituto de Biociências, Universidade Estadual } \\
\text { Paulista, Rio Claro, } 2007 .\end{array}$ \\
\hline D29 & $\begin{array}{l}\text { HENN, R. Desafios ambientais na educação infantil. 2008. } 423 \text { f. Dissertação } \\
\text { (Mestrado em Educação), Centro de Educação, Universidade Federal de Santa } \\
\text { Maria, Santa Maria, 2008. }\end{array}$ \\
\hline D32 & $\begin{array}{l}\text { RUFFINO, S. F. A educação ambiental nas escolas municipais de educação } \\
\text { infantil de São Carlos-SP. 2003. } 117 \text { f. Dissertação (Mestrado em Educação), } \\
\text { Faculdade de Educação - Universidade Federal de São Carlos, São Carlos, } \\
\text { 2003. }\end{array}$ \\
\hline D33 & $\begin{array}{l}\text { TOKITAKA, S. M. M. Educação ambiental, escola e pré-escola: conceito e } \\
\text { experiência. 1997. } 144 \text { f. Dissertação (Mestrado em Supervisão e Currículo), } \\
\text { Pontifícia Universidade Católica, São Paulo, } 1997 .\end{array}$ \\
\hline $\mathrm{T} 2$ & $\begin{array}{l}\text { TIRIBA, L. Crianças, natureza e educação ambiental. 2005. } 249 \text { f. Tese } \\
\text { (Doutorado em Educação), Departamento de Educação, Pontifícia } \\
\text { Universidade Católica, Rio de Janeiro, } 2005 .\end{array}$ \\
\hline T3 & $\begin{array}{l}\text { COSTA, M. C. F. B. A contribuição de Monteiro Lobato para a (re)construção } \\
\text { de concepções e práticas de educação ambiental das professoras de } \\
\text { educação infantil. 2008. } 232 \text { f. Tese (Doutorado em Educação), Faculdade de } \\
\text { Educação, Universidade Federal do Ceará, Fortaleza, } 2008 .\end{array}$ \\
\hline
\end{tabular}

Fonte: Autoria própria (2020).

\section{RESULTADOS E DISCUSSÃO}

A apresentação e discussão dos resultados a respeito das dimensões da educação ambiental presentes nas práticas de educação infantil se apoia em um dos referenciais teóricos que fundamentam esta pesquisa e inspirou as categorias de análise das práticas. Trata-se das três dimensões que se inter-relacionam e se complementam nas propostas para educação ambiental: conhecimentos, valores éticos e estéticos e participação política (CARVALHO, 1989, 1999, 2001, 2006). Partindo inicialmente da apresentação de cada uma dessas dimensões, exploramos os resultados encontrados.

Discutindo a dimensão dos conhecimentos no trabalho com a educação ambiental na educação escolar, Carvalho (2001, p.57) afirma que, em relação às concepções de natureza, tem sido priorizada uma abordagem descritiva e classificatória dos elementos, dos fenômenos e dos processos naturais. Contrapondo-se a essa apresentação isolada e fragmentada "sem considerar as complexas interações entre esses e os constantes e dinâmicos processos de transformação do mundo natural", esse autor indica a pertinência de substituí-la por uma abordagem ecológico-evolutiva.

Carvalho (2006) salienta que os conhecimentos não devem ficar restritos aos aspectos naturais do meio, mas devem incorporar questões relativas à relação do homem (um ser que vive em sociedade) com a natureza, evitando com isso o reducionismo biológico e a análise a-histórica que, buscando explicar a relação da sociedade com a natureza a partir da relação que outras espécies biológicas mantêm com o meio, desconsidera os aspectos históricos e culturais da espécie humana.

No contexto escolar da educação infantil é necessário proporcionar às crianças atividades desafiadoras e problematizadoras, que estejam presentes no 
seu cotidiano, partindo da realidade na qual a escola está inserida e que estejam relacionadas a um pensar sobre os problemas socioambientais, "todas associadas a objetivos claros que busquem proporcionar a descoberta e a criatividade, e a produção e construção do conhecimento pelas crianças" (RODRIGUES, 2011, p. 178).

Segundo Mello (1997, apud MORAES, 2005), tudo pode ser conteúdo na educação infantil. Nessa fase, a criança está em intenso processo de descoberta do mundo, dos objetos, da cultura humana e da linguagem. Com a participação efetiva da criança no planejamento e a escuta atenta do educador, é possível identificar os conteúdos mais significativos a serem trabalhados.

Na leitura dos treze trabalhos, observamos que as temáticas mais abordadas em educação ambiental com as crianças pequenas são: água, fauna, flora, poluição e resíduos sólidos. Os assuntos são, na maioria das vezes, definidos pela professora, mas alguns trabalhos analisados relatam que há flexibilidade no planejamento para incluir outros, de interesse das crianças. Segundo Mello (1999, 2002), uma atividade, compreendida como atividade significativa, envolve o conhecimento do objetivo da tarefa por parte da criança e esse objetivo deve responder a um motivo, necessidade ou interesse dela. Para a autora "só à medida que respondemos ao desejo de conhecimento das crianças promovemos aprendizagem e, consequentemente, desenvolvimento" (MELLO, 1999, p. 21).

Identificamos a preocupação, por parte dos professores investigados, em abordar temas de interesse ou mesmo temas da realidade cotidiana da criança, mas, não envolvem, necessariamente, a discussão das problemáticas socioambientais. Destacamos o trabalho D29 no qual a discussão dos conflitos socioambientais, a reflexão crítica sobre os mesmos e a proposição de ações são objetivos centrais da prática pedagógica da pesquisadora-professora.

Entendemos que, na educação infantil, o conteúdo deve ser tratado de forma vinculada ao cotidiano da criança, emergindo de seus interesses e necessidades. O que não significa abordar somente conteúdos próximos, acessíveis, concretos e simples. Vigotski (2008) destaca a necessidade de a criança se apropriar dos conceitos científicos, do conhecimento elaborado, levando-a a ultrapassar a forma cotidiana de enxergar a realidade (os conceitos espontâneos).

Quanto à importância da abordagem de temas que envolvem a discussão de problemáticas socioambientais, entendemos que os conhecimentos do meio natural, além de serem tratados através de uma abordagem ecológico-evolutiva, devem também abordar a relação dos seres humanos, organizados em sociedade, com a natureza, considerando, inclusive as diferentes modalidades de degradação ambiental. (CARVALHO, 2001). A criança, no seu cotidiano doméstico, tem acesso a uma variedade de informações sobre as questões ambientais. À escola, cabe discutir essas questões na sua relação com a sociedade, interrogando visões fatalistas, reducionistas e a-históricas.

Nos trabalhos D9, T2, T3, D32 identificam-se, segundo suas análises, práticas: de caráter naturalista e concepção utilitarista da natureza; que não incorporam questões relativas à relação do homem com a natureza e as problemáticas socioambientais; com um enfoque descritivo e classificatório dos elementos, dos fenômenos e dos processos naturais; em que a escola perde oportunidades de problematizar questões sobre a vida de outros povos; que não oportunizam às 
crianças o convívio com animais e plantas, as atividades ao ar livre, a exploração e investigação do meio ambiente, a formulação de hipóteses e, ainda, não explora a curiosidade e o interesse das crianças.

Outro dado importante que se destaca, na leitura dos trabalhos, é referente à forma como esses conteúdos são trabalhados na educação infantil. A proposta de desenvolver a educação ambiental na escola por meio de projetos pedagógicos é relatada na maioria dos trabalhos analisados, com exceção do D8 e D9, que não fizeram menção a essa forma de trabalho.

Por seu caráter interdisciplinar e a possibilidade de participação dos alunos e do envolvimento da comunidade local, a proposta de desenvolver a educação ambiental na escola por meio de projetos pedagógicos tem sido apontada por alguns autores. Guimarães $(2004$, p. 32) afirma que essa proposta de trabalho "pode ser metodologicamente viável, desde que os educadores que a realizam, conquistem em seu cotidiano a práxis de um ambiente educativo de caráter crítico". Caso contrário, alerta o autor, esses projetos levarão à reprodução de práticas voltadas às mudanças de caráter individual e comportamental, práticas descontextualizadas da realidade socioambiental em que a escola se insere, mantendo os professores presos ao que chama de armadilha paradigmática.

Precisamos nos atentar, ainda, para os projetos que são elaborados por secretarias ou empresas e encaminhados para as escolas executarem. Os temas podem estar relacionados ao contexto em que os alunos vivem, mas os alunos, seus professores e a escola não participam de sua elaboração. Os projetos de trabalho elaborados sem a participação da comunidade escolar constituem-se em meras técnicas de ensino, fazendo com que o seu potencial de mudança seja perdido e não seja compreendido em um contexto de transformação da educação (PALMIERI, 2011).

Por sua natureza interdisciplinar, o trabalho com projetos na educação infantil oportuniza o trabalho integrado das diversas áreas do conhecimento. Além disso, possibilita trabalhar, de forma integrada e relacionada ao conteúdo de interesse das crianças, as formas produtivas de atividades como os desenhos, artes, culinária, modelagem, construção que, comumente, nas escolas, são desenvolvidas de forma isolada. Para tanto, é importante que o trabalho com projetos permita o envolvimento e a participação das crianças em todas as suas etapas (planejamento, execução e avaliação); oportunize a exploração de diversas fontes de informação (livros, pessoas, vídeos, revistas, jornais, músicas, etc.); permita que a criança avance no desenvolvimento de suas capacidades e habilidades e, por fim, leve em conta a atividade principal através da qual a criança aprende e se desenvolve em cada fase (MORAES, 2005).

Nos trabalhos analisados identificamos: projeto proposto pelo pesquisador (D17); projetos desenvolvidos por empresas ou secretarias (D2, T3); projetos elaborados pela escola ou pelo professor da turma (D2, T2, D21, D25, D26, D28, $\mathrm{D} 32, \mathrm{T3})$; projetos que, mesmo propostos inicialmente pelo professor, sofreram alterações para incorporar assuntos de interesse das crianças (D2, D25, D28, D29, D33).

A leitura dos trabalhos nos revela que a instituição de educação infantil é Página | 9 lugar de apropriação de conhecimentos pelas crianças. Entendemos que essa apropriação não se dá somente na ação direta professor-criança, mas, também é possibilitada (ou não) pelo modo como se organiza o espaço, o tempo (rotina) e 
os materiais com os quais as crianças irão interagir. Essa organização deve favorecer oportunidades de interação, exploração e descobertas pelas crianças, ou seja, deve ser indutora, provocadora de interações da criança com o outro, com o meio e com os materiais e, consequentemente, indutora de aprendizagem e de desenvolvimento.

Nossa análise sobre a dimensão dos conhecimentos nas práticas pedagógicas em educação ambiental na educação infantil, descritas e analisadas nos trabalhos selecionados, permite afirmar que essa dimensão é possível de ser trabalhada na educação infantil, levando-se em conta as atividades típicas de cada faixa etária e atentando para que os conteúdos sejam significativos e desafiadores, ou seja, que não se limitem ao que a criança já sabe.

Discutindo a dimensão dos valores éticos e estéticos, partimos da consideração de que a atual crise ambiental, socioambiental ou civilizatória sinaliza para uma crise de valores, caracterizada por uma dificuldade de refletirmos sobre os problemas do cotidiano e de assumirmos posturas compatíveis com princípios de justiça, respeito e alteridade em relação aos outros seres humanos e à natureza (GUIMARÃES, 2004).

A educação em valores pressupõe práticas pedagógicas que contemplem o trabalho com valores éticos e estéticos (BONOTTO, 2003, 2008 e 2012), e esse trabalho na escola deve começar desde cedo, ainda na educação infantil.

Bonotto (2012) propõe uma educação em valores que contemple, de forma equilibrada, três dimensões que deverão estar sempre interligadas: cognição, afetividade e ação:

a) Cognição: trabalho reflexivo sobre as ideias, crenças, conhecimentos e sentimentos relativos ao objeto ao qual se atribui valor (seja um indivíduo, uma ideia, etc.), de forma a promover uma aproximação com relação aos significados construídos a seu respeito;

b) Afetividade: trabalho de sensibilização e envolvimento, identificação e expressão dos sentimentos pessoais a seu respeito; de apreensão estética em relação a esse objeto;

c) Ação: concretização de situações reais de envolvimento com o objeto valorado, buscando na complexidade das experiências vividas, a serem tanto apreciadas como refletidas, a sua materialização. 0 estabelecimento de um valor, em última instância, se revelará no plano da ação, como um hábito ou atitude coerentes com o que é valorado. (BONOTTO, 2012, p. 45).

A educação em valores extrapola os limites do ajuizamento moral, favorecendo a apreciação estética, intrinsicamente relacionada à arte, aos sentidos, às sensações e às emoções. Através de uma perspectiva de apreciação estética na educação em valores é possível "proporcionar não apenas oportunidades de reflexão sobre um dado objeto valorado [cognição], mas, também, a possibilidade de apreciá-lo esteticamente [afetividade], assim como, quando possível, traze-lo para a prática [ação]" (BONOTTO, 2012, p. 45).

Segundo Bonotto $(2003,2008)$ a experiência estética abre a possibilidade de desenvolvermos um olhar e um agir sensível sobre o outro, sobre a natureza, sobre o mundo, em todas as suas particularidades e diferenças e, consequentemente, estabelecendo uma nova forma de relação. 
Tomando por base os princípios presentes no Tratado de educação ambiental para sociedades sustentáveis e responsabilidade global aprovado no Fórum das Organizações Não Governamentais durante a ECO-92, realizada pela UNESCO no Rio de Janeiro, Bonotto (2008) identifica o que denomina valores ambientalmente desejáveis. Segundo a autora, esses princípios apontam para elementos, práticas e ideias a serem assumidos como valores e que envolvem a: valorização de todas as formas de vida com consequente respeito à biodiversidade; valorização da diversidade cultural; valorização de todas as formas de conhecimento e não somente do conhecimento científico; valorização de uma sociedade sustentável baseada na equidade e qualidade de vida para todos; valorização de uma vida participativa, onde valores como responsabilidade, solidariedade, cooperação e diálogo favoreçam a construção de uma sociedade justa e equilibrada social e ambientalmente.

Observamos que o trabalho com a dimensão dos valores éticos e estéticos na educação infantil está presente nas práticas pedagógicas descritas e analisadas nos treze trabalhos, mesmo que esses valores não correspondam aos valores que os pesquisadores apontam como importantes na sua concepção de educação ambiental, como observamos nos trabalhos D9, T2, T3 e D32. Destacam-se, nos trabalhos D17 e D32, a associação de valores com mudança de hábitos e de comportamento.

Dois termos são bastante recorrentes na leitura dos trabalhos: afetividade e cuidado.

A afetividade é compreendida como inerente às interações das crianças com os outros e com o meio. No trabalho D2, relata-se que a expressão da afetividade (troca de afetos) "é vista e vivenciada sem preconceitos pelas crianças" (2007, p. 37). No trabalho D25, refere-se ao desenvolvimento da criança como cognitivoafetivo. O trabalho D21 discute a indissociabilidade dos aspectos afetivos e cognitivos nos processos de aprendizagem e desenvolvimento da criança, reforçando o quanto as emoções estão presentes quando se busca o conhecimento, de modo que afeto e cognição constituem aspectos inseparáveis, presentes em qualquer atividade, embora em proporções variáveis.

No trabalho D9, associa-se o termo afetividade à apreciação estética. Do mesmo modo, para Bonotto (2003), a afetividade, como uma das dimensões da educação em valores, está intrinsecamente relacionada às dimensões da cognição e da ação. Poderíamos dizer, então, que a afetividade na educação infantil potencializa a cognição e a ação na formação de valores éticos e estéticos.

O cuidado é o outro termo que se destaca nos trabalhos, sendo "considerado, atualmente, como natureza e especificidade da educação infantil" (T2, 2005, p. 71). Compreendemos que o cuidar e o educar, na educação infantil, são atividades que estão intimamente imbricadas. Nos trabalhos analisados, a noção de cuidado é associada ao cuidar de si, ao cuidar do outro e ao cuidar do ambiente. Essa ideia aparece nos trabalhos D2, D8, T2, D21, T3 e D28.

Para o trabalho D2, o cuidado é indissociável da afetividade, ou seja, para cuidar do outro é preciso estabelecer laços de cumplicidade, de afetividade. Afirma que o cuidado (entendido como muito além do cuidado físico) é essencial para a constituição humana, mas são garantidos somente nos documentos oficiais sobre a educação infantil e desaparecem "em documentos que tratam 
dos outros níveis de ensino, como se não precisássemos de cuidados especiais por toda a vida, assim como precisam de cuidados os outros seres que convivem conosco neste planeta" (D2, 2007, p. 49).

No trabalho D8 entende-se que o cuidar do outro e do ambiente implica em cuidar de si, cuidar da formação de sua identidade, de sua personalidade. Segundo Mello (2002, p. 31), a formação da identidade, o conhecimento de si "favorece a formação pela criança de uma imagem de si mesma o que possibilita o cuidado consigo mesma, o gostar e o respeitar a si mesma... condição para ela gostar dos outros e respeitá-los também". Nesse sentido, entendemos que a educação em valores relaciona-se à formação da personalidade da criança, de sua identidade, de sua individualidade.

Portanto, o cuidado do educador com a formação da identidade, da personalidade da criança, pode favorecer (mas não garantir) a formação de valores necessários às ações de cuidado com os outros e com o ambiente.

Para o trabalho T2 (2005, p. 71), ainda hoje, em muitas instituições de educação infantil, existe uma separação entre o educar e o cuidar. Discute o que parece estar na base da polêmica: "o divórcio entre corpo e mente, do qual decorre um outro, o divórcio entre razão e emoção, que, em última análise, revela a cisão básica da sociedade ocidental, entre cultura e natureza". Por essa razão, defende que as atividades ao ar livre não devem visar somente a observação crítica, o conhecimento dos fenômenos naturais, sua classificação e seu domínio, mas proporcionar atividades de apreciação estética da natureza, entendidas como oportunizadoras "de aprendizagens de corpo inteiro, em que são incluídas a atenção curiosa, a contemplação, as sensações, as emoções, as alegrias!" (T2, 2005, p. 207). Segundo esse trabalho, as práticas pedagógicas de muitas instituições de educação infantil estão impregnadas do paradigma moderno da racionalidade, levando a privilegiar a atividade racional como única forma de apreensão de conhecimento.

Segundo Bonotto $(2003,2008)$ a apreciação estética é desinteressada e não visa o conhecimento lógico, mas nos leva a experimentar e observar o objeto na sua totalidade. Entendemos que a apreciação estética da natureza é fundamental na formação de valores estéticos.

O trabalho com valores estéticos não é relatado nos trabalhos D8, D17, D25, D26, D29, D32.

Concluímos que, apesar da dimensão dos valores éticos e estéticos estar presente nos treze trabalhos analisados, a forma como são abordados indicam visões diferentes de educação em valores ambientalmente desejáveis e intencionalidades distintas (conscientes ou não), traduzindo-se em propostas educativas que poderão conduzir a manutenção ou a transformação da forma de relação ser humano-sociedade-natureza. Intencionalmente (ou não), toda prática educativa educa em valores, pois está carregada de valores do professor que a executa; e todo o ambiente da escola é um espaço de vivência de valores.

Considerando a especificidade da educação voltada às crianças, a Teoria Histórico-Cultural aponta o brincar como uma atividade fundamental para o trabalho com valores. Através do brincar, a criança desenvolve sua inteligência e sua personalidade e firma as bases para a formação de valores morais e éticos. 0 jogo de papéis, o faz de conta, na educação infantil, possibilitam a reprodução 
das relações humanas da vida cotidiana e o aprendizado de seus valores e normas. Nessas atividades, a criança interage socialmente, vivencia situações em que problemáticas precisam ser resolvidas e regras e acordos precisam ser discutidos. Portanto, é fundamental a cuidadosa organização do tempo, do espaço, dos brinquedos e objetos, além da mediação do educador, atuando na proposição de temas e discussão dos papéis (MARCOLINO, 2013), não no sentido de coordenar a atividade, mas no de ampliar as ações das crianças.

O brincar como procedimento didático é relatado em 12 (doze) trabalhos, com exceção do trabalho D17, que não faz menção a esse tipo de atividade.

Importante ressaltar que não pretendemos indicar a brincadeira como a única forma de trabalho com a educação em valores na educação infantil. No entanto, lembramos que as interações e as brincadeiras devem ser eixos norteadores das práticas pedagógicas nesse segmento do ensino (BRASIL, 1998), e entendemos que a afetividade e o cuidado devem permear essas atividades.

Para discutir a dimensão da participação política na educação ambiental, partimos da ideia de que essa implica no "desenvolvimento da capacidade de participação política dos indivíduos no sentido de construção da cidadania e de uma sociedade democrática". Essa dimensão pressupõe ainda "o envolvimento e a participação coletiva dos indivíduos na busca de soluções para os diversos problemas ambientais [...]" (CARVALHO, 2001, p. 59). Uma educação ambiental pautada nessa concepção deve buscar práticas pedagógicas "que contribuam para o desenvolvimento de um espírito cooperativo e solidário" (CARVALHO, 2001, p. 60).

Carvalho (2006) destaca o quanto termos como cidadania e democracia têm sido importantes aos ambientalistas e educadores ambientais na proposição de práticas em educação ambiental. Para Rodrigues (2001), o termo cidadania compreende uma condição investida ao cidadão e que se legitima na ação educativa. Para esse autor, a educação enquanto prática política cumpre seu papel de formação para a cidadania ao prover os educandos dos instrumentos necessários e pertinentes: "organização e distribuição de conhecimentos e habilidades disponíveis num certo momento histórico, preparação para o trabalho, acesso ao desenvolvimento tecnológico, participação crítica na vida política" (RODRIGUES, 2001, p. 236).

No contexto da educação infantil, esse ideal de cidadania constituído pelas ideias de autonomia, liberdade e responsabilidade, pode ser discutido a partir do próprio conceito de atividade humana.

Para a Teoria Histórico-Cultural, o ser humano se constitui humano por meio da aquisição de funções psíquicas superiores desenvolvidas através da atividade do sujeito em interação com o meio físico e social, em um determinado contexto histórico, cabendo à escola favorecer experiências de contato com o saber elaborado pela humanidade. Portanto, a atividade é "elemento explicativo da vida humana [...]. Com ela, o ser humano deixa de ser fruto das condições biológicas e torna-se criador de sua vida, capaz de mudar as circunstâncias e criar a própria vida" (FOLQUE; MELLO, 2015, p. 89).

Compreendemos que participação e autonomia são aprendidas quando são vivenciadas no dia a dia da escola e quando a rotina da escola é organizada de modo que a criança seja protagonista. O protagonismo não é transmitido do 
adulto à criança, mas deve ser vivenciado. A criança, desde pequena, deve ser educada para ser protagonista, para ser sujeito da atividade. O protagonismo é uma produção social que deve começar na pequena infância e ser cultivado ao longo da vida (FOLQUE; MELLO, 2015).

Nesse sentido, a escola de educação infantil assume papel relevante, por constituir-se na primeira instituição regulada socialmente com que a criança entra em contato (DUSAVITSKII, 2014).

É precisamente por esta razão que o encontro com a escola é, na expressão de Leontiev, um evento extraordinário. Aqui, nos primeiros meses e anos de ensino, uma qualidade é ou não é formada na criança que subsequentemente pode ser chamada de uma postura cívica (DUSAVITSKII, 2014, p. 79).

A escola de educação infantil deve viabilizar a participação da criança no planejamento do tempo, do espaço, do conteúdo e das experiências, ou seja, na gestão do currículo escolar. Possibilitar o protagonismo da criança pressupõe o reconhecimento, por parte do adulto, de sua capacidade de contribuir nas decisões e, portanto, o direito de ser ouvida.

Para identificar a dimensão da participação política, nas práticas pedagógicas descritas pelos pesquisadores, foi necessário ampliar nosso entendimento dessa dimensão para além de ações coletivas que visem mudanças estruturais na sociedade, proposição de políticas públicas ou ações de controle social da gestão das instituições públicas (BREITING; MOGENSEN, 1999 apud D28, 2007). Os trabalhos que analisamos e os autores que trouxemos em nossa fundamentação teórica nos ajudaram e nos mostraram o caminho.

O trabalho D28, por exemplo, mesmo concordando que a participação política requer o envolvimento em ações coletivas que levem a mudanças mais profundas, aponta que é preciso considerar as especificidades da faixa etária da educação infantil. Explana, ainda, que "a ação coletiva não exclui a ação individual, na verdade, uma completa a outra e fazem parte de um todo mais amplo [...] ambas são necessárias para o desenvolvimento da EA" (D28, 2007, p. 121). Reportando-se a Breiting e Mogensen (1999 apud D28, 2007, p. 121), o trabalho defende que a educação ambiental deve considerar, além do nível estrutural, mais dois níveis: "o individual, onde há conflitos entre necessidades e desejos, expressos como dilemas pessoais; [e] o social, onde há conflitos entre vários grupos ou indivíduos [...]". Desse modo, o trabalho amplia (e não reduz como pode parecer) o conceito de participação política para o individual e o social.

Portanto, a ação individual (e não individualista) como separar resíduos sólidos, economizar água, manter o ambiente escolar limpo, plantar árvores, cuidar da horta, entre outras é também importante e necessária nessa faixa etária na qual os conceitos e valores estão se constituindo.

Com esse entendimento ampliado de participação política, identificamos nos trabalhos analisados relato de práticas que exemplificam cada nível. Podemos afirmar que a ação da criança é identificada em práticas que visam:

a) No nível individual: a (trans)formação, nas crianças, de comportamentos e hábitos pessoais de cuidado com o ambiente natural ou construído 
(D25, D26, D32), a construção da autonomia (D25, D29, D33), o gostar e o cuidar de si (D8, D21, D28) e a construção da identidade (D8).

b) No nível social: a cooperação (D2, D25, D26, D29, D33), a solidariedade (D21), o cuidado, a afetividade em relação ao outro e ao meio cotidiano (D2, D21), o respeito e aceitação às diferenças $(D 8, D 26)$ e o compartilhamento, com sua família, de conhecimentos, valores e ações (D2, D8, D17, D21, D28, D29, D33).

Destacamos que, no trabalho D29, está explícito que as ações individuais precisam ser associadas a ações coletivas, e que as ações imediatas precisam ser associadas a ações sociais mais amplas. Ainda, expõe que a criança, estando ciente das problemáticas ambientais, bem como das ações positivas que outras pessoas estão implementando em busca da sustentabilidade, "pode refletir suas próprias ações, embora que, às vezes pequenas frente às grandes questões ambientais, mas, são maneiras de mostrar e valorizar que elas também podem fazer operações de mudança [...]" (D29, 2008, p. 403).

Diante do exposto, podemos afirmar que a dimensão da participação política está presente nas práticas pedagógicas descritas e analisadas pela maioria dos trabalhos analisados, exceto nos trabalhos D9 e T2.

No trabalho D9, relata-se que, nas creches investigadas: a organização do espaço e do tempo da criança não favorece o desenvolvimento da autonomia; o ambiente e a rotina das crianças são planejados e organizados de modo a atender às necessidades dos adultos, e de modo que movimentos e ações das crianças possam ser controlados, vigiados e disciplinados; os interesses e desejos das crianças não são considerados.

No trabalho T2, relata-se que as crianças das creches investigadas permanecem, a maior parte do tempo, aprisionadas às salas, sujeitas às normas que impossibilitam seu acesso aos espaços abertos, em nome da segurança e da disciplina. O aprisionamento dos corpos e dos desejos cerceia, também, a possibilidade de a criança desenvolver a capacidade de fazer escolhas sobre as diversas tarefas e atividades do dia a dia, ou seja, não favorecem a construção da autonomia e da capacidade de participação.

Todas as ações de participação política envolvendo crianças pequenas precisam ser precedidas de um trabalho, por parte do professor, de disponibilizar para a criança os conhecimentos necessários para que ela possa discutir, buscar informações, refletir e então propor ações, com autonomia de pensamento e de ação, sem ser induzida, manipulada ou adestrada. Assim como Rodrigues (2001), entendemos que a participação na vida social compreende uma participação consciente, ou seja, o domínio do pensamento crítico, a capacidade de distinguir o conteúdo dos diversos discursos, para que a participação não se dê por manipulação ideológica ou por adestramento ambiental (BRÜGGER, 2004). E a participação consciente está relacionada à aquisição da capacidade de efetuar escolhas com autonomia, liberdade e responsabilidade (RODRIGUES, 2001).

\section{CONSIDERAÇÕES FINAIS} separada de cada uma dessas dimensões, elas são indissociáveis: a participação 
política não se faz, de forma consciente, sem a apropriação dos conhecimentos necessários à compreensão das complexas relações que envolvem os problemas socioambientais; a capacidade de efetuar escolhas com autonomia, liberdade e responsabilidade depende da formação de valores éticos e estéticos constituídos em um ambiente de participação democrática, afetividade, diálogo e respeito mútuo, ou seja, considerando a criança como sujeito ativo. Para que essas três dimensões se efetivem são imprescindíveis a formação e o desenvolvimento pleno das capacidades humanas - da inteligência e da personalidade - através de um processo educativo que assuma seu papel de humanização do ser humano desde o seu nascimento.

Importante ressaltarmos que, na perspectiva da Teoria Histórico-Cultural, a efetiva apropriação dos conhecimentos, dos valores éticos e estéticos e da participação política se concretiza quando o proposto pelo professor se constitui para a criança em atividade ou vivência.

Quanto à dimensão dos conhecimentos, verificamos que, apesar de estar presente nos treze trabalhos selecionados, a forma como os conteúdos são abordados indicam concepções diferentes de educação ambiental e intencionalidades distintas (conscientes ou não). Essas concepções se traduzem em propostas educativas conservadoras ou críticas quanto à abordagem de conteúdos referentes à relação cultura-natureza e as problemáticas socioambientais.

Enfatizamos, ainda, que, por seu caráter interdisciplinar e a possibilidade de participação dos alunos e do envolvimento da comunidade local, a proposta de desenvolver a educação ambiental na escola por meio de projetos pedagógicos é apontada pela maioria dos pesquisadores. Mas, identificamos, em algumas práticas relatadas, a ausência de participação das crianças nas decisões sobre o planejamento e a execução desses projetos, o que nos leva a questionar a compreensão desses professores sobre o trabalho por meio de projetos e a própria construção de conhecimentos pelas crianças.

$\mathrm{Na}$ identificação e análise da presença da dimensão de valores éticos e estéticos, observamos a intenção, por parte dos professores cujas práticas são investigadas, de formar valores envolvendo: a cooperação, a solidariedade, a autonomia, a sensibilidade, o respeito às diferenças, a afetividade e o cuidado.

A dimensão cognitiva da educação em valores está presente nas práticas relatadas. Parte do entendimento de que a aquisição de conhecimento pode levar à sensibilização ou à conscientização e, portanto, leva a uma valoração que implicará em mudança de comportamento e de hábitos.

A dimensão da afetividade da educação em valores também aparece, e é trabalhada em atividades de valorização estética da natureza e de interação com elementos naturais. Igualmente, aparece associada ao cuidado. A valorização do cuidado e do afeto podem conduzir a experiências éticas, atitudes e modos de agir ambientalmente favoráveis à diversidade, a qualidade de vida e a cidadania. O entendimento de cuidado é associado ao cuidar de si, ao cuidar do outro e ao cuidar do ambiente.

A experiência de apreciação estética da natureza, que valorize as sensações, é importante e necessária na educação infantil, mas não devem se reduzir a um caráter contemplativo, sem reflexão e problematização. Entendemos que as 
experiências de apreciação estética da natureza envolvem a dimensão afetiva da educação em valores e não podem ser secundarizadas em relação às dimensões cognitiva e ação, pois essas três dimensões são inter-relacionadas.

Para a identificação e análise da presença da dimensão da participação política, nas práticas pedagógicas em educação ambiental na educação infantil descritas nas pesquisas, buscamos ampliar o conceito de participação para além da capacidade do sujeito de participar em ações coletivas que visem mudanças profundas na estrutura da sociedade. Dessa forma, consideramos que, na educação infantil, a participação política se efetiva com mais frequência no nível individual e no social.

Nesse entendimento, poderíamos dizer que a participação da criança no nível individual é identificada não apenas em comportamentos e hábitos pessoais de cuidado com o ambiente natural ou construído, mas, também, na construção da identidade e da autonomia intelectual, do gostar e do cuidar de si. No nível social a participação é identificada em ações de cooperação, solidariedade, cuidado com o outro e com a natureza, a afetividade, o respeito e aceitação das diferenças, bem como em ações de compartilhamento, com sua família, de conhecimentos, valores e ações - o que não impede ações mais amplas abrangendo, por exemplo, reivindicações ao poder público, mas, com a devida cautela para não se resumirem em práticas esvaziadas de significado e de compreensão para as crianças.

Apesar de termos clareza de que as ações nos níveis individual e social não são suficientes para o exercício pleno da capacidade de participação política, consideramos que elas são necessárias na educação infantil. A criança experimentando a responsabilidade de cuidado consigo, com o outro e com o ambiente em que vive, poderá, a partir desse aprendizado, pensar e agir em contextos mais amplos.

Por fim, é importante destacar a observação de que falta a alguns dos professores, que tiveram suas práticas investigadas, uma teoria pedagógica que oriente essas práticas para uma perspectiva crítica, compatível com suas intenções e discurso relatados, ou seja, as pesquisas indicam a necessidade de uma teoria pedagógica que se alinhe à Educação Ambiental Crítica e ajude o professor a pensar e tomar decisões sobre sua prática.

Indicamos que, dada a relevância desse assunto, é necessário que mais pesquisas sejam realizadas com o objetivo de refletir e construir junto com o professor da educação infantil conhecimentos que deem suporte às suas práticas. Concomitantemente, devemos dar visibilidade a essas experiências, divulgando seus resultados e contribuindo para o enriquecimento e a orientação das práticas pedagógicas em educação ambiental de outros professores na educação infantil, bem como inspirando práticas de professores de outras etapas do ensino, principalmente, os dos anos iniciais do ensino fundamental. 


\title{
Environmental education and early childhood education in Brazilian dissertations and theses: knowledge, values and political participation present in the pedagogical practices reported
}

\begin{abstract}
This article is an excerpt from the master's research linked to the interinstitutional project called Environmental education in Brazil: analysis of academic production (dissertations and theses) - EArte. The research is based on Historical-Cultural Theory to understand children's learning and development in the perspective of a Critical Environmental Education that contemplates three dimensions: knowledge, ethical and aesthetic values and political participation. We seek to identify and analyze the presence of these three dimensions in pedagogical practices in environmental education in the school context of early childhood education reported in thirteen Brazilian dissertations and theses. It is a qualitative research, characterized as a documentary research, with a bibliographic character, as a state of the art type. Regarding the dimension of knowledge, the results considered as more thematic are water, fauna, flora, pollution and solid waste. The proposal of developing the work through pedagogical projects is reported in eleven of the thirteen papers, but some practices reveal the loss of children's participation in decisions that involve the planning and execution of these projects, or what leads us to question the understanding of these teachers about work through pedagogical projects and about the knowledge construction by children. Regarding the dimension of ethical and aesthetic values, we identified on the teachers, whose practices we are looking into, an intention to form values using: cooperation, solidarity, autonomy, sensitivity, sensitivity, respect for differences, affectivity and care. Pedagogical practices that include a dimension of political participation are related in eleven of the thirteen papers and they are carried out, more frequently, at the individual and social levels. The studies show the need for a pedagogical theory that aligns Critical Environmental Education and help teachers to think and make decisions about their practice.
\end{abstract}

KEYWORDS: Environmental education. Child education. Pedagogical practices. 


\section{NOTAS}

1. Os números não são sequenciais porque os trabalhos selecionados para o presente artigo fazem parte de um volume de 38 (trinta e oito) trabalhos analisados na dissertação.

\section{REFERÊNCIAS}

ALBERTO, P. G. Educação ambiental e educação infantil numa área de proteção ambiental: concepções e práticas. 2007. 196 f. Dissertação (Mestrado em Educação), Instituto de Biociências, Universidade Estadual Paulista, Rio Claro, 2007.

BARDIN, L. Análise de conteúdo. 4. ed. Lisboa: Edições 70, 2009.

BONOTTO, D. M. B. O trabalho com valores em educação ambiental: investigando uma proposta de formação contínua de professores. 2003. $231 \mathrm{f}$. Tese (Doutorado em Educação) - Centro de Educação e Ciências Humanas, Universidade Federal de São Carlos, São Carlos, 2003.

BONOTTO, D. M. B. Contribuições para o trabalho com valores em educação ambiental. Ciência \& Educação, Bauru, v. 14, n. 2, p. 295-306, 2008. Disponível em: <http://www.redalyc.org/pdf/2510/251019505008.pdf>. Acesso em: 14 abr. 2020.

BONOTTO, D. M. B. Educação ambiental e o trabalho com valores. In: BONOTTO, D. M. B.; CARVALHO, M. B. S. S. (Orgs.). Educação ambiental e o trabalho com valores: reflexões, práticas e formação docente. São Carlos: Pedro \& João Editores, 2012. p. 35-55.

BRASIL. Ministério da educação. Secretaria de educação fundamental. Referenciais curriculares nacionais para a educação infantil. Brasília: MEC/SEF, v. 1-3, 1998.

BRASIL. Lei no 9795, de 27 de abril de 1999. Dispõe sobre a educação ambiental, institui a política nacional de educação ambiental e dá outras providências. Diário Oficial da União, Brasília, DF, 28 abr. 1999. Seção 1. p. 1.

BRÜGGER, P. Educação ou adestramento ambiental? 3. ed. Florianópolis: Letras Contemporâneas, 2004. 200 p.

CARVALHO, L. M. A temática ambiental e a escola do 10 grau. 1989. 282 f. Tese (Doutorado em Educação) - Faculdade de Educação, Universidade de São Paulo, São Paulo, 1989.

CARVALHO, L. M. Educação e meio ambiente na escola fundamental: perspectivas e possibilidades. Projeto, Porto Alegre, ano 1, n. 1, p. 35-39, jul. 1999. 
da educação. Secretaria de educação fundamental. Coordenadoria geral de educação ambiental (Coea), 2001. p. 55-63. Disponível em:

http://portal.mec.gov.br/secad/arquivos/pdf/educacaoambiental/panorama.pdf. Acesso em: 14 abr. 2020.

CARVALHO, L. M. A temática ambiental e o processo educativo: dimensões e abordagens. In: CINQUETTI, H. S.; LOGAREZZI, A. (Orgs.). Consumo e resíduos: fundamentos para o trabalho educativo. São Carlos: Edufscar, 2006. p. 19-41.

DUSAVITSKII, A. K. Educação desenvolvente e a sociedade aberta. Ensino Em ReVista, Uberlândia, v. 21, n. 1, p. 77-84, jan./jun. 2014. Disponível em: http://www.seer.ufu.br/index.php/emrevista/article/view/25053/13890. Acesso em: 14 abr. 2020.

FOLQUE, M. A. C.; MELLO, S. A. Criar uma comunidade com crianças dos 3 aos 6 anos: o desenvolvimento pessoal e social na infância. In: ANJOS, C. I.; FERREIRA, F. I. (Orgs.) Infância e Educação: olhares sobre contextos cotidianos. 1 ed. Maceió: Edufal, 2015. p. 89-104.

FRANCO, M. L. P. B. Análise de conteúdo. 3 ed., Brasília: Liber Livro, 2008.

GUIMARÃES, M. Educação ambiental crítica. In: LAYARARGUES, P. P. (Org.). Identidades da Educação Ambiental Brasileira. Brasília: MMA/DEA, 2004. p. 2534.

LAYRARGUES, P. P.; LIMA, G. F. C. As macrotendências político-pedagógicas da educação ambiental brasileira. Ambiente \& Sociedade, São Paulo, v. 27, n. 1, p. 23-40, jan./mar. 2014. Disponível em:

http://www.scielo.br/pdf/asoc/v17n1/v17n1a03.pdf. Acesso em: 14 abr. 2020.

LUCCAS, M. B. Práticas pedagógicas em educação ambiental na educação infantil: análise de dissertações e teses brasileiras. 2016. 241 f. Dissertação (Mestrado em Educação) - Instituto de Biociências, Universidade Estadual Paulista, Rio Claro, 2016.

LÜDKE, M.; ANDRÉ, M. E. D. A. Pesquisa em educação: abordagens qualitativas. 2 ed. São Paulo: EPU, 2015.

MARCOLINO, S. A mediação pedagógica na educação infantil para o desenvolvimento da brincadeira de papéis sociais. 2013. 185 f. Tese (Doutorado em Educação) - Faculdade de Filosofia e Ciências, Universidade Estadual Paulista, Marília, 2013.

MELLO, S.A. Algumas implicações pedagógicas da Escola de Vygotsky para a educação infantil. Pro-Posições, Campinas, v. 10, n. 1 (28), p. 16-27, mar. 1999. Disponível em: https://www.fe.unicamp.br/pf-fe/publicacao/1990/28-artigosmellosa.pdf. Acesso em: 14 abr. 2020.

MELLO, S. A. A Educação das Crianças de Zero a Três Anos. Texto elaborado para 
Ciência na Universidade Estadual Paulista, Unesp, Marília - 2002 (disponibilizado pela autora em formato word).

MELLO, S. A. Infância e humanização: algumas considerações na perspectiva histórico-cultural. Perspectiva, Florianópolis, v. 5, n. 1, p. 83-104, jan./jun. 2007. Disponível em:

https://periodicos.ufsc.br/index.php/perspectiva/article/viewFile/1630/1371.

Acesso em: 14 abr. 2020.

MORAES, L. A. Y. O trabalho com projetos na educação infantil. 2005. 82 f.

Dissertação (Mestrado em Educação), Centro de Educação e Ciências Humanas, Universidade Federal de São Carlos, São Carlos, 2005.

MORAES, R. Mergulhos discursivos: análise textual qualitativa entendida como processo integrado de aprender, comunicar e interferir em discursos. In: GALIAZZI, M. C., FREITAS, J. V. (Orgs.) Metodologias emergentes de pesquisa em educação ambiental. 2. ed. Ijuí: Unijuí, 2007. p. 85 - 114.

PALMIERI, M. L. B. Os projetos de educação ambiental desenvolvidos nas escolas brasileiras: análise de dissertações e teses. 2011. 189 f. Dissertação (Mestrado em Educação) - Instituto de Biociências, Universidade Estadual Paulista, Rio Claro, 2011.

RODRIGUES, C. Educação infantil e educação ambiental: um encontro das abordagens teóricas coma a prática educativa. REMEA - Revista Eletrônica do Mestrado de Educação Ambiental, [S.I.], n. 26, p. 169 - 182, jan./jun. 2011. Disponível em: http://www.seer.furg.br/remea/article/view/3354. Acesso em: 14 abr. 2020.

RODRIGUES, N. Educação: da formação humana à construção do sujeito ético. Educação \& Sociedade, Campinas, v. 22, n. 76, p. 232-257, out. 2001.

ROMANOWSKI, J. P.; ENS, R.T. As pesquisas denominadas do tipo "estado da arte" em educação. Diálogo educacional, Curitiba, v. 6, n. 19, p. 37-50, set./dez. 2006. Disponível em:

http://www2.pucpr.br/reol/pb/index.php/dialogo?dd1=237\&dd99=view\&dd98= pb. Acesso em: 14 abr. 2020.

RUFFINO, S. F. A educação ambiental nas escolas municipais de educação infantil de São Carlos-SP. 2003. 117 f. Dissertação (Mestrado em Educação), Faculdade de Educação - Universidade Federal de São Carlos, São Carlos, 2003.

VIGOTSKI, L. S. Pensamento e linguagem. 4. ed. São Paulo: Martins Fontes, 2008. 
Recebido: 04 maio 2020

Aprovado: 15 jul. 2020

DOI: $10.3895 /$ actio.v5n2.12187

Como citar:

LUCCAS, M. B.; BONOTTO, D. M. B. Educação ambiental e educação infantil em dissertações e teses brasileiras: conhecimentos, valores e participação política presentes nas práticas pedagógicas relatadas. ACTIO, Curitiba, v. 5, n. 2, p. 1-22, mai./ago. 2020. Disponível em: <https://periodicos.utfpr.edu.br/actio> Acesso em: XXX.

Correspondência:

Marinete Belluzzo Luccas

Avenida 42, n. 519, Vila Operária, Rio Claro, São Paulo, Brasil.

Direito autoral: Este artigo está licenciado sob os termos da Licença Creative Commons-Atribuição 4.0 Internacional.

(c) (1) 